that it would be appropriate for these applications.

Presidential Campaign! is a smooth running and professional looking program that would make an excellent addition to a course on political behavior, the presidency, or campaigning.

\title{
Can American Social Science Majors Acquire an International Perspective?
}

\author{
Remi Clignet, University of Maryland, College Park
}

Concern is growing over the lack of sensitivity that American social sciences students display toward the rest of the world (Brademas 1983; Tiryakyan 1986; Shenon 1989; Hechinger 1989). In economic terms, this insensitivity is seen as preventing free trade; in political terms, as hampering effective diplomacy. In scientific terms, it prevents a proper use of comparative methods.

Since the curriculum represents an "ideological superstructure," innovations will alter students' world views only if they have been preceded by changes in the organization of academic institutions and disciplines. The effectiveness of curricular innovations requires a tightening of the links among disciplines and universities. Further, the effectiveness of these innovations depends also on a dialectic resolution of the tensions between the purity of disciplines and their relevance to the abilities and aspirations of students. Because students initate the beliefs and behaviors of their familial, academic, and disciplinary environments, these three environments combined should determine the range of the reforms proposed (Bourdieu et Passeron 1964, 1970). ${ }^{1}$

\section{Provincialism of the Culture At Large}

"Most of the students at an overwhelming majority of institutions of higher learning are simply going through their careers without exposure to any non-American experience" (Harf 1970). As this lack of exposure reflects the insensitivity of many American parents to international events, its origin is manifold. It results in part from the latent isolationism of American culture. When Americans describe themselves as a nation of "immigrants in time," they emphasize the need to renew constantly the ideological justification of their lives. Their search for self-identity combines the rejection of the past and the dream of a future held synonymous with continuous progress (Bellah et al. 1984).

\section{"Most of the students at an overwhelming majority of institutions of higher learning are simply going through their careers without exposure to any non-American experience",}

In contrast to Europeans who value highly the "moss" of the past and its traditions, Americans hold that it is a good thing that "rolling stones gather no moss." But this blindness to time and history usually dulls sensitivity to other voices and other shores. ${ }^{2}$ Despite the relentless efforts of some Americans to promote international cooperation and to enhance the status of the United Nations or of UNICEF, many of their countryfolks are attracted by isolationism. ${ }^{3}$ Whether the economic and political dominance of the United States in the world is asserted by Americans themselves or acknowledged by the international community, it lowers individual sensitivity to other cultural and political entities. Indeed, Pax Americana does not pre- dispose American adults or students to acquire a critical knowledge of other viewpoints or cultures.

The immensity of the country and the attraction exerted by a mythical West have helped Americans to focus their attention inward rather than outward. In contrast to Gemeinschaft-like cultures where personal identity evolves as a result of social transactions with local significant others, American mythology and the notion of the "imperial Self" emphasize the role played by mobility in the definition of the Self (Anderson 1971). Since mobility entitles individuals to "try everything at least once" (Bellah et al. 1984) or, "if something does not work here, to try it elsewhere," it generates a superficial mode of social interaction that is rarely challenged.

To illustrate, Americans had no difficulty singling out high school chemistry or physics programs as the major cause of the country's inability to immediately match the success of the Soviet Sputnik. In contrast, they have been more reluctant to appreciate the consequences imputed to their lack of international sensitivity and, for example, to appreciate "what was and is in the mind of the Iranian population" (Hechinger 1987). "The point is that this environment teaches students to be indifferent to whatever fails to stir the enthusiasm of their teachers and parents.

\section{Provincialism Fostered by Academic Decentralization}

Two major factors tend to impede or prevent any improvement in the teaching of international skills. First, the independence of colleges and uni- 
versities fragments the collective vision that Americans have of international issues. While educational decentralization fosters variations in educational experiences, there is no political or cultural mechanism that would enable students, faculties, and academic administrators to interpret the variability of their perceptions in a single, coherent, theoretical framework. The absence of such a framework explains why international initiatives are judged on economic rather than academic terms. In a society where market forces prevail, international sensitivity becomes an academic "good" that competes with others on the shelves of educational supermarkets and other "credentializing factories" (Collins 1979). Since this specific good is treated interchangeably as one form of public cultural capital and as one variety of private economic capital, its intrinsic value is constantly undermined. The ensuing confusion explains the vagueness of the controversies provoked by the plan to establish a National Foreign Language Center entitled to formulate a national strategy in teaching foreign languages. These controversies seem to be caused as much by private rivalries as by competing conceptions of the task.

Secondly, the specialization of knowledge and the ensuing isolation of disciplines prevents the development of an effective internationally oriented curriculum. ${ }^{5}$ The New York

\section{The specialization of knowledge and the ensu- ing isolation of disciplines prevents the development of an effective interna- tionally oriented curriculum.}

Times warnings of the declining skills of young Americans in mathematics and in the knowledge of foreign cultures (Fiske 1987) gives the unfortunate impression that even though the two areas of decline are inter- related, they are two distinct phenomena. In this sense, the hurdles confronting the teaching of multidisciplinarity, or at least the institutionalization of systematic links across disciplines, may be a metaphor for international relations. ${ }^{6}$

\section{Provincialism of the Disciplines}

The effects of the parochialism of the society at large or of its academic institutions on the global knowledge of students vary across fields. Social sciences majors are at the bottom of the distributions of mean scores on tests that tap this kind of knowledge (Barrow 1981: 65). ${ }^{7}$

The poor performance of students reflects three dilemmas faced by the social sciences. First, social scientists rely on epistemology rather than hermeneutics to evaluate the validity of competing specialties and theories (Rorty 1979, chapter 7; Collins 1989). ${ }^{8}$ The curriculum of many departments conveys the impression that there is a consensus on what constitutes an orthodox discourse. This enables professors not only to label the theories and assumptions they disapprove of as being unscientific or irrelevant, but also to feel excused from teaching them. Today, a more democratic presentation of competing theories stands as a prerequisite to international education.

The second dilemma concerns the articulation between macro and micro levels of analysis, as evidenced by the differential use of assimilation in the various social sciences (Clignet 1981). For psychologists, the verb "to assimilate" is transitive and concerns the inward reduction of the outside world to the subject's preexisting framework. In contrast, the way in which sociologists or political scientists use that verb masks tensions in the respective roles of subjects and objects in the process under study. As an example, sociologists or political scientists explore whether minorities "assimilate, are assimilating or are assimilated into" [sic] American society." Yet, the haphazard use of transitive and intransitive forms and of active and passive voices highlights the ambig- uities inherent in the explanations offered of the emerging equality of political, economic, or educational opportunities. Is the equality achieved by minorities due to the generosity of elites, and if so, what has triggered such an altruism? Conversely, is this equality contingent on the sacrifices of the minorities who want to belong to the mainstream? If so, when did their endeavors begin? When and why have these sacrifices been acknowledged and rewarded by elites? Acting as a source of identity conflict among minorities (Fanon 1953), the ambiguous use of the concept of assimilation prevents also the understanding of the bonds between minorities and the larger society.

Finally, in the same way that the preeminence accorded to equality over identity in the explanations of ethnicity masks as much as it explains the relations between insiders and outsiders, it reveals parallel ambivalences in the definition and value of cross-cultural comparisons. Ethnic studies seek primarily to explain the differential life chances of national groups in terms of the length of their stay in the New World (Lieberson 1980); or of how they are perceived by other groups who preceded them in America (Greeley 1978). At the same time, there is hardly any natural history of the mechanisms of selective adaptation or retention that have structured the lives and social arrangements of successive generations of each national group following their arrival in the New World. There is hardly any account of the extent to which migrants have retained in the new world the rules that governed marriage or divorce, child-bearing and rearing, or the accumulation and the transfer of wealth in the societies from which they came. ${ }^{9}$

To conclude, social science majors can hardly be expected to be sensitive to international relations as long as their disciplines do not invent a new style to deal with competing ideas as well as with competing social classes, ethnic groups, or nation-states.

Indeed, these students can hardly be expected to understand the recurrent dialectics between the convergent effects of changes in the distribution of societal goods and the divergent influences of cultural identity (Worsley 1984; Moore 1979). 


\section{Some Proposals}

Insofar as the insensitivity of social science majors to a global understanding reproduces effectively the isolationism of families, universities, and of disciplines themselves, curricular changes can only be limited. Most important, the effectiveness of these changes depends on organizational innovations.

\section{Organizational Innovations}

Internationalizing the curriculum requires integrating all academic international endeavors into a coherent framework. First, programs of studies in foreign countries (notably junior years abroad) should be streamlined. Currently, such programs are often implemented without any input from American social scientists who remain indifferent to developing systematic links with their equivalents abroad. Yet, students cannot take the notion of global vision seriously as long as they do not perceive it to be a core concern of their instructors. ${ }^{10}$

To start with, students' experiences abroad should be centered around research projects involving American and foreign institutions, for example, around objects of international competition. European and California universities could explore jointly the social aspects of wine growing and drinking. Similarly, European or Japanese and midwestern institutions could examine the dysfunctions of the automobile industry. This joint approach would highlight variations in the outcome of cooperative and competitive relations and, hence, in the relative contributions of insiders and outsiders. In doing so, students and faculties would also discover the need to distinguish structural and cultural processes, and for instance, to differentiate modernization from Americanization, Gallicization, or Russification.

Even if departments reaffirm their commitment to a foreign language, they must still specify their expectations in this regard. Students are prone to interpret the bureaucratic pluralism displayed toward languages and, notably, the equivalences acknowledged between the mastering of any foreign language and any computer language (Fortran, etc.) as signs of indifference. ${ }^{11}$ In effect, departments should require the knowledge of a specific foreign language, the nature of which should be guided by their own theoretical and empirical concerns. The ensuing restriction of choices might appear unduly oppressive, but it symbolizes the professional integration of the various components of an international education.

\section{Departments should} require the knowledge of a specific foreign language, the nature of which should be guided by their own theoretical and empirical concerns.

International sensitivity cannot blossom as long as the relevant parts of the curriculum are treated as a specific track or specialty. The isolation of courses or programs such as comparative methods, women or black studies, and their lack of integration into a coherent and unifying framework prevents students from appreciating the relativity of differences. As an illustration, American textbooks on social problems give the impression that remedies are made in the USA and only in the USA. This inhibits exploring research in other countries. Alternatively, the same textbooks may also give the impres-

\section{American textbooks on social problems give the impression that remedies are made in the USA and only in the USA.}

sion that certain behaviors, practices, or beliefs considered to be problematic (ethnic strifes, authoritarianism, etc.) are only to be found elsewhere than the United States. For instance, the literature on F scales and authoritarianism suggests unduly that the corresponding syndrome is a trait unique to Nazi Germany. Hence, the purpose of internationalizing the curriculum cannot be merely to offer new credit hours.

\section{Curricular Innovations}

To make a difference to the global understanding of social science majors, curricular changes must lower tensions between the search for the purity of the discipline, and the search for its relevance (Thompson 1979). Indeed, the difficulty of teaching social sciences is a byproduct of the clash between the substantive or the methodological challenges of the field and students' abilities and aspirations.

The Search for Purity. The internationalization of the curriculum is not about facts. Nor is it about teaching more systematically that Buenos Aires is the capital city of Argentina, or that Eskimos have a significantly larger number of words than Americans to describe snow. Rather, internationalization is about the origin, the manifestations, and the consequences of the relativity of the social sciences. Insofar as this relativity concerns theory, internationalizing the curriculum seeks to achieve a better understanding of the origin and consequences of the tensions between theoretical styles (Brown 1977: 53-56). Insofar as this relativity concerns methods, internationalizing the curriculum seeks to highlight the variability of social facts throughout space and time and the ensuing limitation of the validity of the theories tested.

Internationalization is about the origin, the manifestations, and the consequences of the relativity of the social sciences.

Most important, insofar as both theories and methods concern the 
relationship of the social science disciplines to the public (Gans 1989), they are both reflections on and of relations between insiders and outsiders. As such, they show how such relations are sources of knowledge as well as of errors, and of change as well as of resistance to change. Thus Simmel $(1950,127)$ explores the conditions under which "human beings prefer to make personal statements or confessions to relatively strange people, even though the corresponding communication does not yet make the relationship an intimate one." His article could serve as an introduction to the powerful, yet underused collection of essays edited by Beteille and Madan (1975), in which various anthropologists examine how their gender and their national origin have affected their observations in India, in the Indian diaspora, and in Indian reservations in America. As a counterpoint to this analysis of the perceptions of strangers in an alien environment, the reading of Tocqueville and Martineau could help students understand the perceptions of others in a context with which they are familiar.

As Merton shows (1973), the distinction between insiders and outsiders also helps identify the conditions under which it is most appropriate for indigenous agents of change to ask "foreigners" to "spill the beans" on their behalf. For example, a number of American social scientists understood the debilitating effects of racism and overt discrimination long before World War II. By the same token, they understood also that their status as insiders reduced their ability to correct the situation. It remained necessary for them to identify the foreigner (outsider) who could efficiently plead for new racial policies. Even though writers like Gandhi or Senghor would have empathized most intensely with the plight of the oppressed, their conclusions would have not made any impression on white elites. American scientists had to choose a spokesman whose national background was "impeccable" and whose country had little to do with race relations. Gunner Myrdal was the best spokesman, and even though $A n$ American Dilemma did not necessarily break new ground, it still repre- sented the most effective type of message.

In short, these pieces throw complementary light on the mechanisms governing the collection of data that are relevant to public and private interactions and on the processes by which the conclusions generated enter into the public domain. The first set of authors (Simmel, Beteille, and Maldan) deal with the private consequences of the distinction between insiders and outsiders; Merton, with their public implications. While Merton's piece on insiders and outsiders serves to explain to undergraduates what differentiates insiders from outsiders, or what distinguishes outsiders from one another, it also helps them to assess the functional relativity of these distinctions. Some strangers are better than others for accomplishing tasks that insiders themselves cannot perform successfully.

The Search For Relevance. Yet, curricular changes designed to enhance cross-cultural sensitivity are unlikely to have any impact as long as they are not focused on students' cognitive, emotional, and normative orientations. It will simply not do to expect social science majors to manipulate, say, world systems theories, as long as the underlying "evidence" remains cold and alien to their vision. Since college experiences correspond to a phase of the life cycle that is simultaneously selfcentered and altruistic, the contributions of global understanding to the discipline might be enhanced through systematically exploring the subjective experiences that students have of their national origin. ${ }^{12}$ Since to learn about others is to learn about oneself, this exploration may help them understand the multifaceted aspects of the notion of "sociological ambivalence" (Merton and Barber 1963), and hence, of the contradictions they experience as Americans and as heirs of a particular tradition. Thus, social science majors will learn to appreciate the variety of forms taken by oppression (Memmi 1968). They will also learn that ethnicity in America is not only about inequality or about the differential access of distinct national groups to valuable assets, but also about identity and "com- munities of memories" (Bellah et al. 1985). Equally important, they will also learn about the patterns of retention and selective adaptation of individual or collective beliefs and practices, as they affect bilingualism (Grosjean 1982), patterns of marriage (Fitzpatrick 1981), or rituals (Yaganisako 1978).

\section{Conclusions}

The provincial beliefs and practices of American undergraduates reproduce those of their parents and of their instructors. Exploring this assumption can help in assessing the optimal range of changes for enhancing cross-cultural sensitivity. By the same token, the effectiveness of innovations requires organizational changes and a greater and more focused commitment on the part of faculties. Finally, the ideological changes symbolic of a greater global understanding concern both the purity of the various disciplines and their relevance to students. On the one hand, internationalizing a discipline should not introduce a new "enclave"; rather, it should systematically explore how to avoid theoretical imperialisms as well as methodological biases. On the other hand, this internationalization must be anchored in the undergraduate experience.

Yet, the results of the exploration are doomed to remain sterile as long as faculties act as if undergraduates were interchangeable units rather than autonomous subjects who experience conflicting hopes and despairs. As the acquisition of a global vision requires a cognitive and emotional understanding of the interdependence between the United States and any other country, as well as between every American and any individual citizen of any other country, this acquisition requires learning about both the universality and the singularity of the human condition.

\section{Notes}

1. This reproduction may be mechanical or interpretive. In the first case, students' behaviors and beliefs are literal copies of the three categories of adults to which we refer in the main text, mainly their parents, their 
teachers, and their mentors in the discipline itself. In the second case, these beliefs and behaviors are symbolically equivalent to those of the three categories of adults.

2. In his novel The Go Between L. P. Hartley evokes this relation between time and space: "The past is a foreign country: they do things differently there" (1953: 11). Of course, the rejection of the past and the preceding generations is selective. Philip Roth has recently underlined the increasing rhetorical attention that politicians give to the sufferings of their immigrant parents, after the latter's arrival in the promised land. But this does not necessarily imply a greater sensitivity to the "old country."

3. Further, McCarthy's rhetoric was, at least in part, targeted against international understanding, which was equated with being soft on Communism.

4. The persistence of private economic or political deals despite diplomatic tensions between the two governments has not contributed to reduce this inability.

5. The segmenting effects of decentralization are also visible in the lack of coordination in the stances taken by U.S. governors and the federal government in this regard (Hechinger 1989; Shenon 1989) or the policies adopted toward undergraduates on the one hand and graduates on the other.

6. Resistance to team teaching offers a case in point. In addition, team teaching is often reduced to a simple-minded quantitative sharing of the hours or of the themes to be treated.

7. Mathematics and history students obtain the highest scores. Both disciplines have less ambiguous definitions of time and space than sociology; mathematics, because the discipline tends to impose abstract definitions upon these two a priori categories of human experiences, and history, because the discipline acknowledges fully their relativity.

8. The hostility displayed toward the revisionist stance (1982) of Gergen on the limits of the ahistorical research generated by a positivistic social psychology underlines the preeminence attached to orthodoxy over hermeneutics in the field. This preeminence and the blindness to history that goes with it characterizes all theoretical schools, including symbolic interactionism (Sennett 1978; Fabiani 1986).

9. Socio-psychological studies dealing with ethnic variations in child-rearing practices (Davis 1946: 698-710) or in cognitive styles (Lesser et al. 1965) are scattered and have not become parts of mainstream social sciences.

10. The timing of the concern over the lack of sensitivity to international life is particularly puzzling in view of the continuous growth of the population of foreign students present on American campuses. The coexistence of these two phenomena constitutes another illustration of the continuous fragmentation of academic processes. Thus, the lack of coordination in the reform of undergraduate and graduate education constitutes another factor preventing the internationalization of the curriculum.
11. In effect, this pluralism can be read as a perversion of the concept of generalized other. Indeed the equality of the status of German, Japanese, or Russian as prerequisites represents also a denial of their specificity. Most serious, there is no commitment on the part of sociology departments to foster cooperative bonds with foreign language departments.

12. Further, the distinction between minorities and foreigners is often tenuous. To learn about Latinos or about the Nisei is to learn about Latin America and about Japan.

\section{References}

Anderson, Q. 1971. The Imperial Self. New York: Knopf.

Barrows, T. 1981. "College Students' Knowledge and Beliefs: A Survey of Global Understanding." Change Magazine Press.

Bellah, R. et al. 1985. Habits of the Heart: Individualism and Commitment in American Life. Berkeley: University of California Press.

Beteille A., and T. N. Madan. 1975. Encounter and Experience. Honolulu: Hawaii University Press.

Bourdieu, P. and J. C. Passeron. 1964. Les Heritiers. Paris: Editions de Minuit. 1970. La Reproduction. Paris Editions de Minuit.

Brademas, J. 1983. "The Importance of Learning About the Rest of the World." Chronicle of Higher Education, April 21.

Brown, Richard. 1977. A Poetic for Sociology: Toward a Logic of Discovery in the Social Sciences. New York: Cambridge University Press.

Brown, Roger. 1965. Social Psychology. New York: The Free Press.

Clignet, R. 1981. "Natural History of Educational Interactions." Comparative Education Review 25: 330-52.

Collins, R. 1979. The Credential Society. New York: Academic Press. .1989. "Sociology: Proscience or Anti

' Science." American Sociological Review 54: 124-39.

Davis, A. 1946. "Social Class and Color Differences in Child Rearing." American Sociological Review 11: 698-710.

Fabiani, J. L. 1986. "From graven images. Patterns of modern materialism." Revue Francaise de Sociologie 27 (3): 565-68.

Fanon, F. 1952. Peaux Noires et Masques Blancs. Paris: Le Seuil.

Fiske, E. 1987. "Global Focus on Quality in Education." New York Times, January 6.

Fitzpatrick, J. 1981. "The Puerto Rican Family." In Ethnic Families in America: Patterns and Variations, ed. C. Mindel and R. Habenstein. New York: Elsevier, 189-214.

Gans, H. 1989. "Sociology in America: The Discipline and The Public." American Sociological Review 54: 1-16.

Gergen, K. 1982. Toward a Transformation in
Social Knowledge. New York: Springer Verlage.

Greeley, A. 1978. The American Catholic. New York: Basic Books.

Harf, J. 1970. Report on Undergraduate International Studies. President's Cormmission on Foreign Language and International Studies.

Hartley, L. P. 1968. The Go Between. New York: Avon.

Hechinger, F. 1978. "Cultural Isolation." New York Times, Tuesday, January 13. 1989. "About Education." New York Times, Wednesday, March 15.

Kuhn, T. 1970. The Structure of Artistic Revolutions. Chicago: University of Chicago Press.

Lesser, G., F. Fifer and D. Clark. 1965. Mental Abilities of Children from Different Social Class and Cultural Groups. Monographs of the Society for Research in Child Development, $30,4$.

Lieberson, S. 1980. A Piece of the Pie. Berkeley: University of California Press.

Memmi, A. 1968. The Dominated Man. Boston: Beacon Press.

Merton, R. 1973. The Sociology of Science. Chicago: University of Chicago Press.

Merton, R. and E. Barber. 1963. "Sociological Ambivalence." In Sociological Theories, Values and Socio-Cultural Change, ed. E. Tiryakian. Glencoe, NY: The Free Press, 97-120.

Moore, W. 1977. World Modernization: The Limits of Convergence. New York: Elsevier.

Sennett, R. 1978. The Fall of Public Man. New York: Vintage Books.

Simmel, G. 1950. The Sociology of George Simmel. Glencoe, NY: The Free Press.

Thompson, M. 1979. Rubbish Theory. Oxford: Oxford University Press.

Rorty, R. 1979. Philosophy and the Mirror of Nature. Princeton: Princeton University Press.

Shenon, P. 1989. "Governors Warning of An Ignorant U.S." New York Times, February 26.

Tiryakian, E. 1986. “Sociology's Great Leap Forward: The Challenge of Internationalization." International Sociology 1 (2): 155-71.

Worsley, P. 1984. The Three Worlds: Culture and World Development. Chicago: University of Chicago Press.

Yaganisako, S. J. 1978. "Variations in American Kinship: Implications for Cultural Analysis." American Ethnologist 5: 15-29.

\section{About the Author}

Remi Clignet is a professor of sociology at the University of Maryland, College Park. He is currently attached to ORSTOM, a research institute in Paris. 